\title{
Incidence of and Causes for Ventriculoperitoneal Shunt Failure in Children Younger Than 2 Years: A Systematic Review
}

\author{
Amr Ali Hasanain ${ }^{1}$ Ahmed Abdullah ${ }^{1}$ Mohamed F. M. Alsawy ${ }^{1}$ Mohamed A. R. Soliman ${ }^{1}$ \\ Ammar Ali Ghaleb ${ }^{1} \quad$ Reem Elwy ${ }^{1} \quad$ Ahmed A. M. Ezzat ${ }^{1} \quad$ Ahmed Al Menabbawy ${ }^{1,2}$ Ahmed A. Marei ${ }^{1}$ \\ Bassante Abd el Razik ${ }^{1}$ Mostafa I. El Hamaky ${ }^{1}$ Henry W. S. Schroeder ${ }^{2}$ Steffen Fleck ${ }^{2}$ \\ Ahmed El Damaty ${ }^{1,2}$ Sascha Marx ${ }^{2}$ Stephan Nowak ${ }^{2}$ Jörg Baldauf ${ }^{2}$ Ahmed Zohdi ${ }^{1}$ \\ Ehab Ahmed El Refaee ${ }^{1,2}$
}

1 Department of Neurosurgery, Cairo University Kasr Alainy Faculty of
Medicine, Cairo, Egypt
${ }^{2}$ Klinik für Neurochirurgie, Ernst-Moritz-Arndt Universität, Greifswald,
Germany J Neurol Surg A 2019;80:26-33.
Address for correspondence Amr Ali Hasanain, MSc, Department of Neurosurgery, Cairo University Kasr Alainy Faculty of Medicine, Cairo 11562, Egypt (e-mail: doctor.amrali@gmail.com).

\begin{abstract}
Keywords

- failure

- infants

- infection

- obstruction

- ventriculoperitoneal shunt
\end{abstract}

Objectives Ventriculoperitoneal (VP) shunting is commonly used to treat pediatric hydrocephalus, but failure rates are high. VP shunt failure in children is mostly caused by infection and/or proximal/distal shunt obstruction. However, to our knowledge, no previous reviews have discussed this topic using only clinical studies when age-related data could be obtained. This systematic review aimed at reevaluating what is already known as the most common causes of shunt failure and to determine the incidence and causes of VP shunt failure during the first 2 years of life as a step to establish solid evidence-based guidelines to avoid VP shunt failure in infants.

Methods We performed a search using the search terms "Cerebrospinal Fluid Shunts" (Medical Subject Headings [MeSH]) AND failure [All Fields] AND ("humans" [MeSH] AND English [lang] AND "infant" [MeSH]). Only articles that specifically discussed VP shunt complications in children $<2$ years were included.

Results We found that the most common causes of VP shunt failure in children $<2$ years were shunt obstruction and infection, both observed in a range.

Conclusion VP shunt failure is very common in infants, mostly resulting from obstruction and infection. Future studies should focus on methods designed to avoid these complications or on alternative treatments for hydrocephalus.

\section{Introduction}

For many patients with hydrocephalus, the primary management option is the implantation of a VP shunt as an effective cerebrospinal fluid (CSF) diversion technique shunting the CSF from the cerebral ventricles to the peritoneal cavity. The management of pediatric hydrocephalus is more challen-

received

March 7, 2018

accepted

May 3, 2018

ging, and the reported rates of shunt obstruction and infection are high. ${ }^{1-3}$ Nonetheless, this is the procedure of choice for treating infants because its success rate is greater than that for endoscopic third ventriculostomy (ETV). ${ }^{4}$ Despite having a lower incidence of short-term failure than ETV, long-term complications of VP shunting are more frequent, and failure results in high rates of morbidity and mortality. ${ }^{5}$

(c) 2019 Georg Thieme Verlag KG Stuttgart · New York
DOI https://doi.org/ 10.1055/s-0038-1669464. ISSN 2193-6315. 
Many factors may contribute to shunt failure in infants and subsequently to poor outcomes. First, several factors predispose infants to shunt failure including prematurity, low birth weight $(<1,500 \mathrm{~g})$, infection, and abnormal levels of total leukocyte count, red blood cells, proteins, and glucose in the CSF before shunt insertion. ${ }^{6,7}$ Second, after shunt implantation, failure can result from obstruction of the ventricular or peritoneal end of the shunt, infection, shunt fracture, shunt migration, or overdrainage. Infants are more vulnerable to fatal outcomes as a result of shunt failure than older children and adults. The surgical technique, postoperative wound care, type of shunt used, and general condition of the infant all contribute to the success rate of the shunt procedure and survival.

It is common sense that VP shunt failure in children is most commonly caused by infection and/or proximal/distal shunt obstruction. However, to our knowledge, no previous review has discussed this issue using the specific criteria included in this study. This systematic review aimed at reevaluating what is already known as the most common causes of shunt failure and to determine the incidence and causes of VP shunt failure during the first 2 years of life as a step to establish solid evidence-based guidelines to avoid VP shunt failure in infants.

The German Academic Exchange Service has funded a project to develop evidence-based guidelines for the prevention of VP shunt failure among infants. ${ }^{8}$ As part of this project, we performed a systematic review of the current literature to identify the incidence of VP shunt failure during the first 2 years of life and the most common causes of failure.

\section{Methods}

The outline of our search strategy was planned with reference to the Preferred Reporting Items for Systematic review and Meta-Analysis for Protocols. We limited our search of the/Medline database to studies published in English through 2015 in which the patients were infants ranging in age from birth to 23 months. We used the following search terms (-Fig. 1) from/Medline:

1. "Cerebrospinal fluid shunts" [Medical Subject Heading]

2. Number 1 AND "failure" [All]: 1,378

3. Limit to humans: 1,366

4. Limit to English: 1,287

5. Limit to infants aged 0 to 23 months: 491

We applied the following inclusion criteria to the search results: children $<2$ years of age who experienced VP shunt failure. We excluded reviews, systematic reviews, and metaanalyses, as well as studies that did not report quantitative data regarding complications. Only articles that specifically analyzed the target issues were included.

A total number of 462 articles were excluded after abstract reading. Those articles were irrelevant to the target question of our study, or the age group $<2$ years was not clearly identified, or the number of patients was not sufficient as we excluded case reports. Studies that did not focus

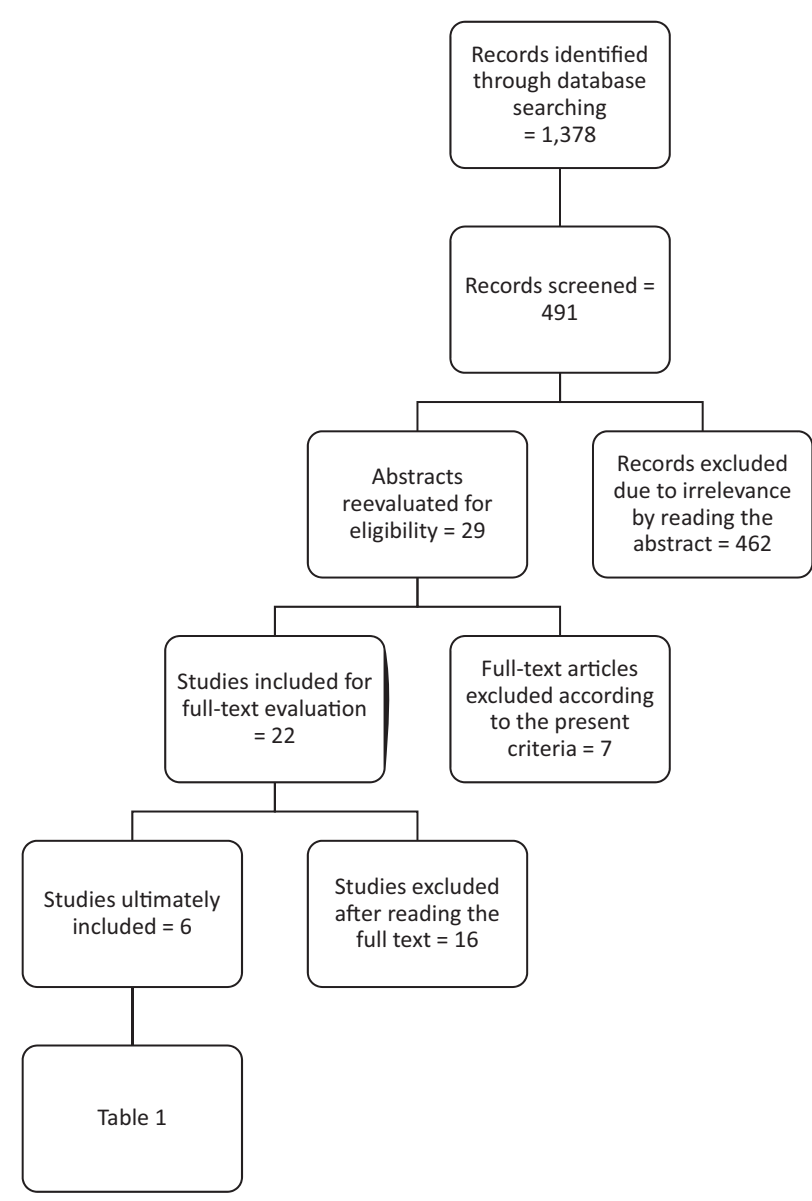

Fig. 1 Tabular flow chart of the review process.

on VP shunt failure, such as those with ventriculoatrial/ ventriculopleural shunts and any type of shunt other than VP shunt, were excluded. Any study with mixed-age groups in which the age group $<2$ years is not specified was excluded.

We generated a list of titles from all the included studies, and two independent groups of researchers performed critical reviews to evaluate all abstracts. Studies that did not provide answers to the target questions were excluded. For each study, any conflicting opinions between the two groups were resolved by consensus after analyzing the complete study (not only the abstract). Case reports, studies evaluating a single shunt type that reported a conflict of interest with the manufacturer, and studies with poor evidence and small sample sizes for the relevant patient groups were excluded.

\section{Results}

The search yielded 29 studies that provided answers to the target questions. We subsequently reevaluated their abstracts and excluded seven of them either due to irrelevance to the study topic or absence of clear data required in our inclusion criteria such as the exact age group or the type of CSF shunt. Next, the two independent groups thoroughly evaluated the full text of the remaining 22 studies through critical analysis of each one, ultimately excluding 16 for the 
reasons just mentioned. Thus six studies were included in the final analyses (- Fig. 1).

These six studies were recorded in a master table ( - Table 1) constructed to facilitate data review and analysis. The study type and a summary of the findings can be seen for each article. Analysis of the data was performed, and then the conclusion and final recommendations for future research were generated based on the strength of the data.

Shannon et $\mathrm{al}^{9}$ reviewed 237 patients $<6$ months of age at the time of shunt implantation. Of those patients, 130 experienced shunt failure (54.85\%) within a follow-up period of 2 years. Most shunt failures were caused by infection or a proximal obstruction. The incidence of failure was greater in children $<3$ months of age at the initial VP shunt insertion and in children who weighed $<2 \mathrm{~kg}$ at the initial insertion.

Beez et al $^{10}$ examined shunt failure in 36 patients $<1$ year of age. Twenty-three patients (64\%) experienced shunt failure.

As a special entity of shunt placement, Garber et $\mathrm{al}^{3}$ compared the survival of patients who received a fourth ventricle shunt placed via transtentorial or suboccipital stereotactic approaches. They found that shunts failed in $82.8 \%$. The causes were proximal obstruction (51.7\%), infection (17.2\%), or distal obstruction (13.8\%). This was the highest failure rate identified in our review and highlights the impact of poor entry points and shunt-tip locations on VP shunt outcome.

Miranda et $\mathrm{al}^{2}$ studied VP shunt obstruction in 103 patients with posthemorrhagic hydrocephalus and found that 42 VP shunts (40.8\%) developed an initial proximal obstruction within 120 months of follow-up, 8 of these had a previous shunt infection of a total of 13 shunt infections (12.62\%), and 34 cases had obstruction without a previous infection.

Turhan et al $^{11}$ studied 38 newborns $<1$ year of age in whom multiple shunt malfunctions were reported. Shunt infection was the most frequently reported cause of failure (19 failures), followed by distal obstructions (14 failures), proximal obstruction (13 failures), and four valve malfunctions and four pseudocysts. Total migration of the shunt was reported twice, and two trapped ventricles (one lateral ventricle and one fourth ventricle), two subdural hemorrhages, one shunt disconnection, and one shunt with incorrect placement of the ventricular catheter were also reported. These malfunctions required one revision in 28 cases, two revisions in 6 cases, three revisions in 4 cases, and four revisions in 1 case.

Bakhsh et al $^{1}$ studied 100 infants $<1$ year of age including 75 cases of congenital hydrocephalus and 25 cases of post-pyogenic hydrocephalus. Shunt failure was caused by either an infection or obstruction. Fourteen patients presented with infection (14\%): four patients with acute shunt infection, four cases of wound dehiscence and exposure of shunt material, and six cases with necrosis of the skin in the neck and upper chest overlying the shunt tube). Ten patients had shunt obstruction (10\%), five within the first year and five within the second year postoperatively.

Our review confirmed, that the most common causes of ventriculoperitoneal (VP) shunt failure in children $<2$ years were shunt obstruction and infection. Obstruction was observed in a range starting from $10 \%{ }^{1}$ reaching $40.8 \%$ in shunts for posthemorrhagic hydrocephalus ${ }^{2}$ and $51.7 \%$ in fourth ventricular shunts. ${ }^{3}$ Infection was observed in 12.6 to $17.2 \%$ of VP shunt implants.

\section{Discussion}

We started our study with a global screening of literature for studies focused on VP shunt failure. With every step of our research, we read each single abstract for the possibility of beneficial data for this systematic review. Finally we found that 22 abstracts, and performed a full-text reading after which we excluded 16 more studies and finally included 6 studies.

It was challenging to exclude some of the most important studies that provided strong evidence regarding VP shunt failure. As mentioned, we wanted to remain focused on the inclusion criteria we agreed on, so we included only studies of VP shunt failure in children $<2$ years of age. Our aim was to analyze whether the failure rates that occur overall in children are the same as those of children $<2$ years.

An example of studies excluded during abstract reading is the study of Simon et al, "Risk Factors for First Cerebrospinal Fluid Shunt Infection: Findings from a Multi-center Prospective Cohort Study." ${ }^{12}$ In spite of the significance of this study, it focused only on first time failure due to infection whose results would negatively affect our review.

Another example of the high-quality studies we excluded after a full-text reading is Notarianni et al, "Congenital Hydrocephalus and Ventriculoperitoneal Shunts: Influence of Etiology and Programmable Shunts on Revisions."13 This study used the median age with no clear data on age on implantation and the follow-up period.

Likewise, in the study by Kulkarni et al, "Outcomes of CSF Shunting in Children: Comparison of Hydrocephalus Clinical Research Network Cohort with Historical Controls," ${ }^{14}$ the incidence of VP shunt failure in the age group $<2$ years could not be clearly identified, and the study was subsequently excluded.

Likewise, the study by Riva-Cambrin et al, "Risk Factors for Shunt Malfunction in Pediatric Hydrocephalus: A Multicenter Prospective Cohort Study." ${ }^{15}$ was excluded, because they analyzed together subduro-peritoneal shunts to treat subdural hygromas and VP shunts.

(-Table 2) shows the 16 studies excluded after full-text reading,

Finally, we analyzed the six studies that met all of our inclusion criteria, and, as expected, shunt obstruction and infection were the most common causes of VP shunt failure in infants $<2$ years. Premature infants had a higher risk of shunt failure. ${ }^{10}$ Intraventricular hemorrhage (an underlying cause of hydrocephalus), a younger age, and a lower weight at the time of initial shunt placement were shown to be directly correlated with an increased risk of VP shunt failure. ${ }^{3,10}$ On the other hand, the case series reported by Miranda et $\mathrm{al}^{2}$ indicated that rates of shunt obstruction in 


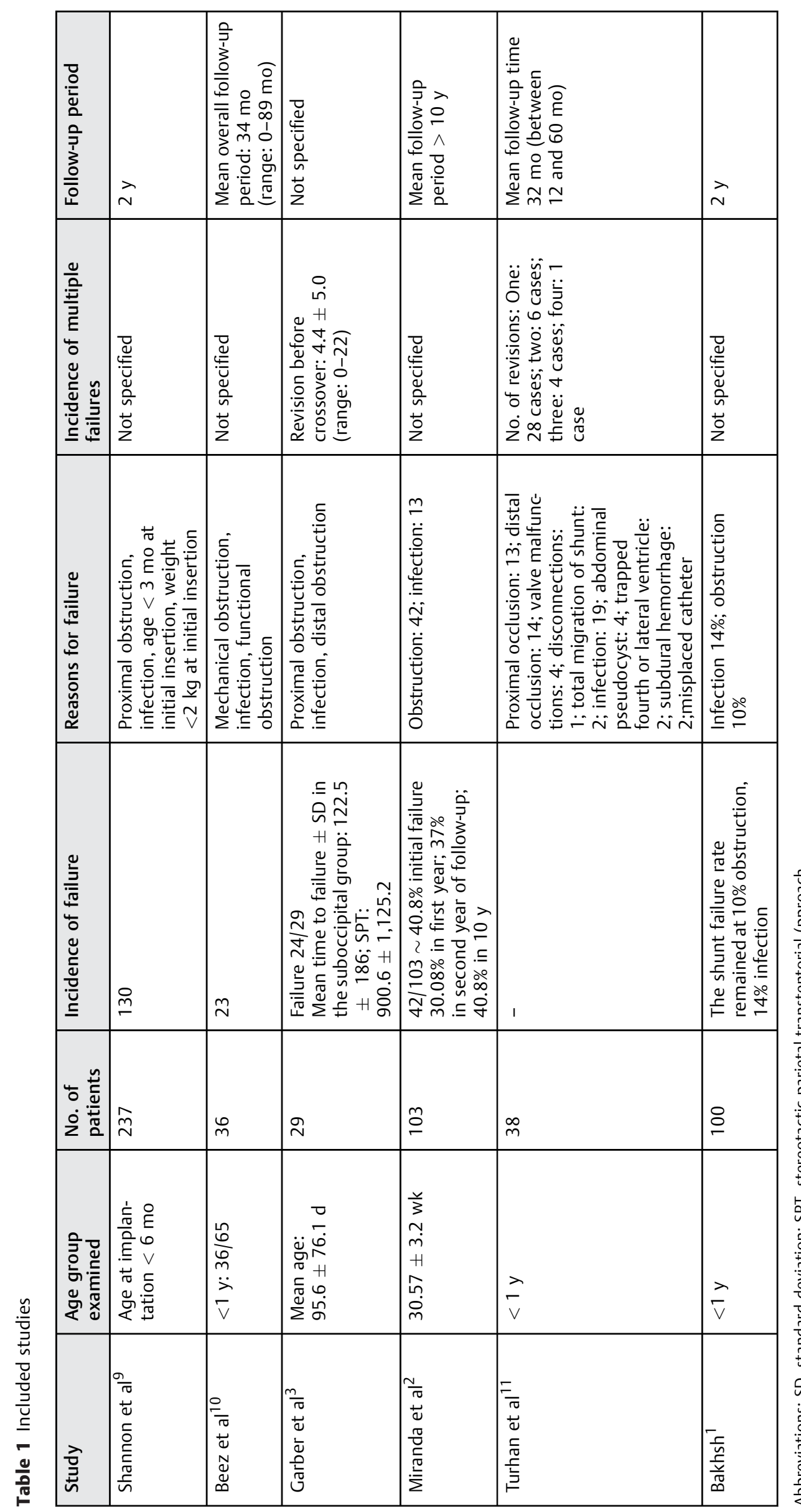




\begin{tabular}{|c|c|c|c|c|c|c|c|c|}
\hline 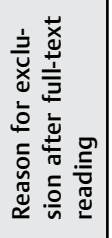 & 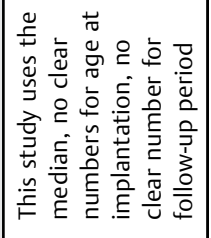 & 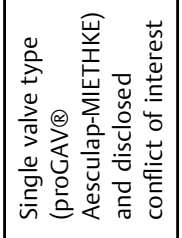 & 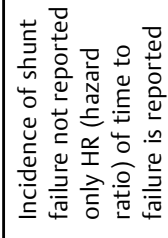 & 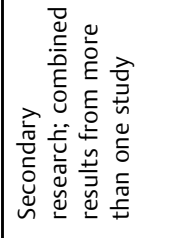 & 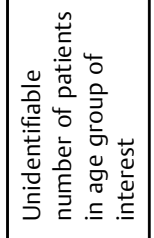 & 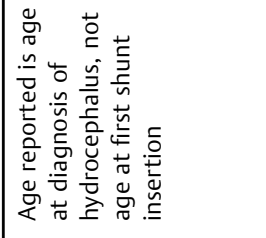 & 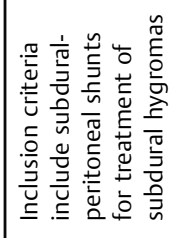 & 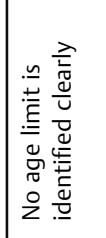 \\
\hline 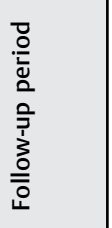 & 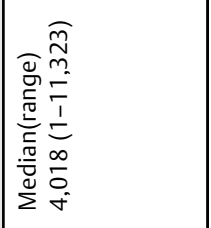 & $\mid \begin{array}{l}0 \\
E \\
2 \\
\infty \\
1 \\
1 \\
\text { N }\end{array}$ & 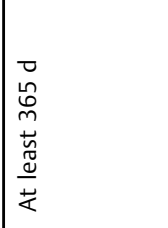 & $\Sigma$ & $\begin{array}{l}\check{\Xi} \\
\infty \\
-\end{array}$ & 1 & 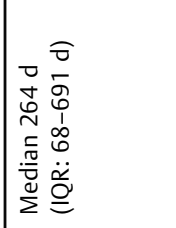 & 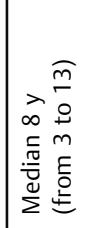 \\
\hline 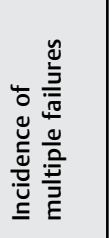 & 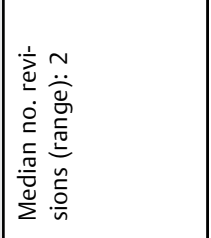 & 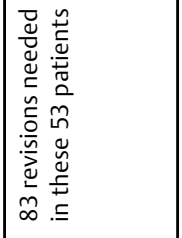 & 1 & $\frac{s}{z}$ & 1 & 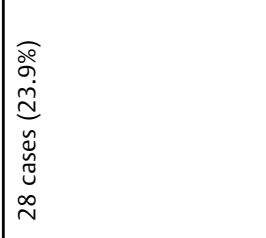 & 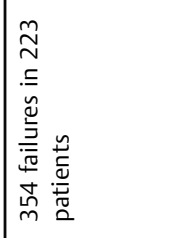 & $\Sigma$ \\
\hline 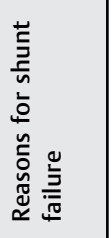 & 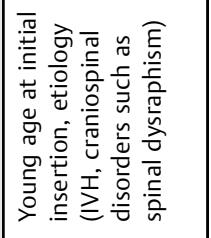 & 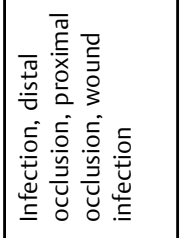 & 1 & $\Sigma$ & 1 & 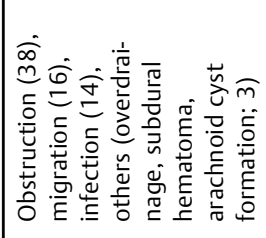 & 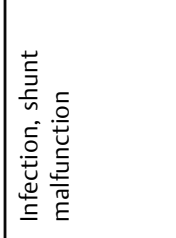 & $\Sigma$ \\
\hline 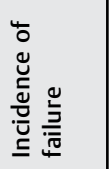 & 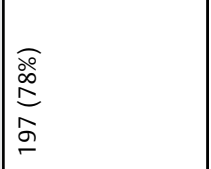 & $\frac{\tilde{m}}{\hat{\mu}}$ & | & 文 & $\stackrel{m}{q}$ & $\frac{\kappa}{\kappa}$ & 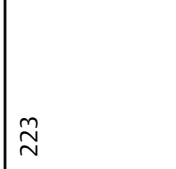 & 文 \\
\hline 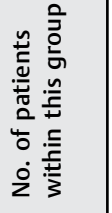 & $\stackrel{\stackrel{n}{N}}{\text {. }}$ & 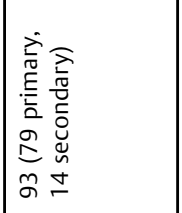 & 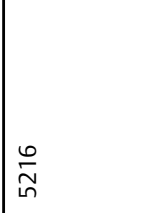 & \begin{tabular}{|l}
$\stackrel{\sim}{N}$ \\
$\stackrel{\sim}{\sim}$
\end{tabular} & 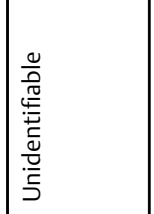 & $\pi$ & in & 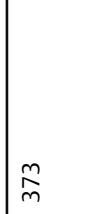 \\
\hline 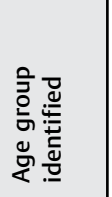 & 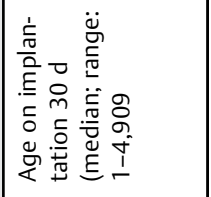 & 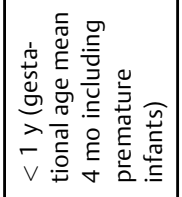 & $\frac{\lambda}{v}$ & $\frac{\lambda}{v}$ & $\vec{i}$ & $\frac{\lambda}{v}$ & $\begin{array}{l}\stackrel{O}{E} \\
\text { } \\
\vee\end{array}$ & 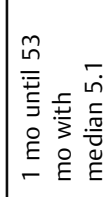 \\
\hline 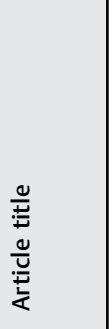 & 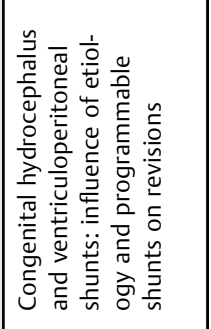 & 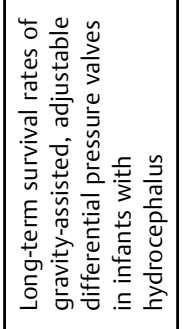 & 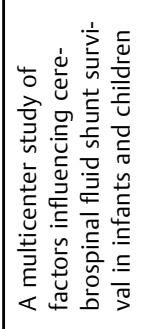 & 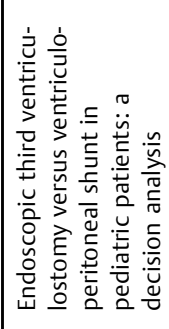 & 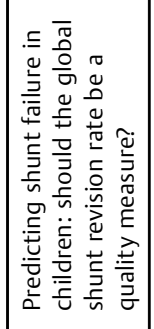 & 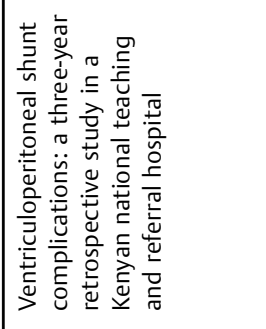 & 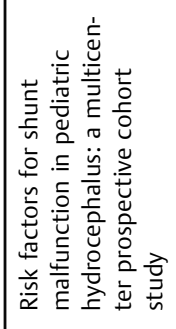 & 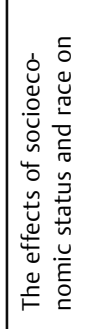 \\
\hline 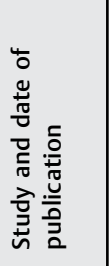 & 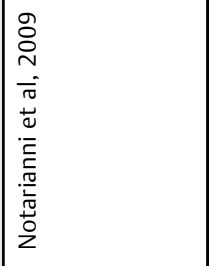 & 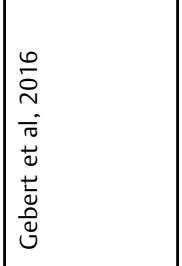 & 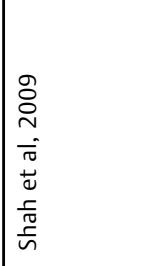 & 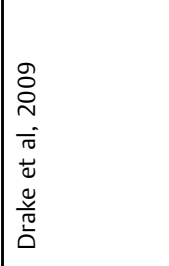 & 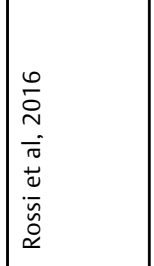 & 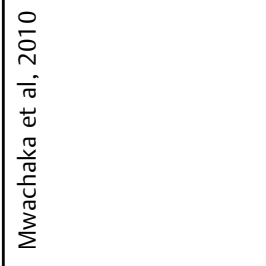 & 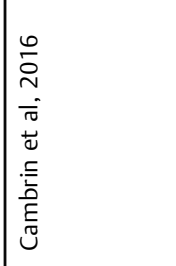 & 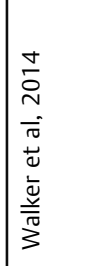 \\
\hline
\end{tabular}




\begin{tabular}{|c|c|c|c|c|c|c|c|c|}
\hline 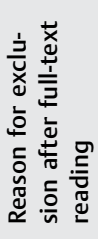 & 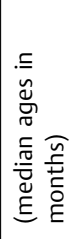 & 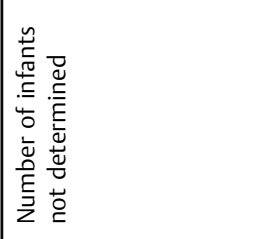 & 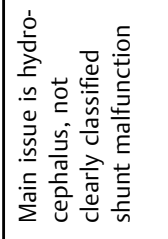 & 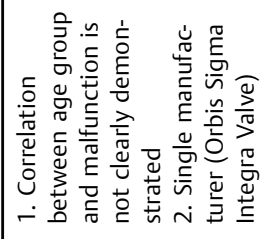 & 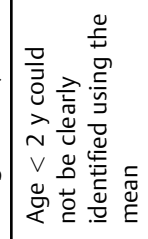 & 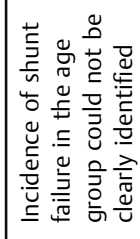 & 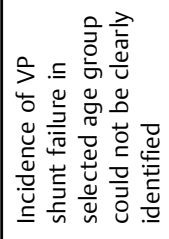 & 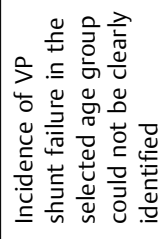 \\
\hline 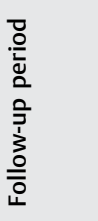 & & & & & & & & \\
\hline 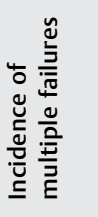 & & & & & & & & \\
\hline 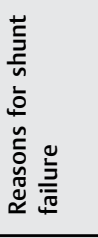 & & 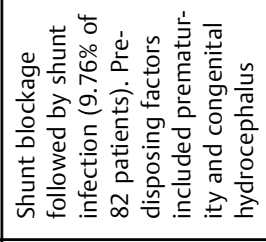 & & & & & & \\
\hline 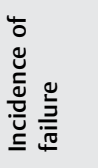 & & 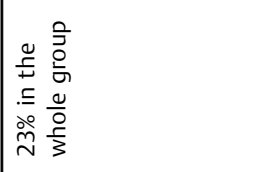 & & & & & & \\
\hline 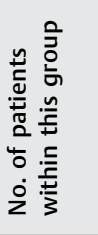 & & 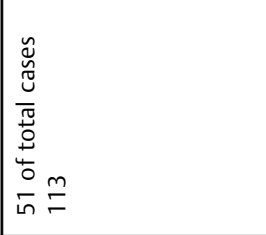 & & 每 & & $\hat{0}$ & & \multirow{2}{*}{ 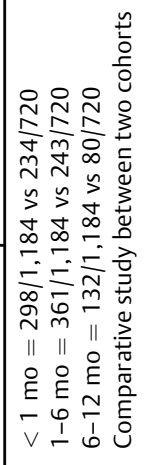 } \\
\hline 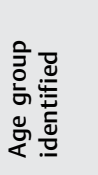 & & 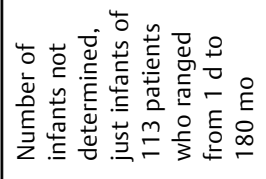 & & \begin{tabular}{|l}
$O$ \\
$E$ \\
$\varrho$ \\
$V$ \\
$V$
\end{tabular} & & $\begin{array}{l}\stackrel{O}{E} \\
m \\
\text { V }\end{array}$ & & \\
\hline 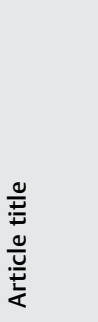 & 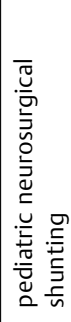 & 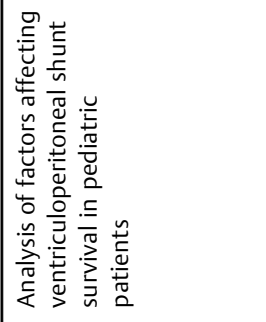 & 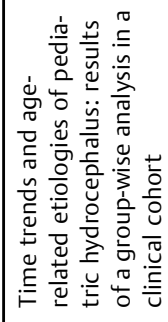 & 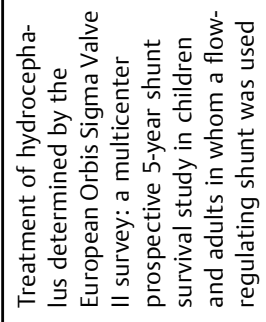 & 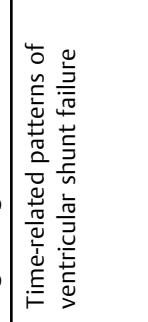 & & 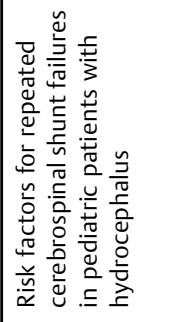 & 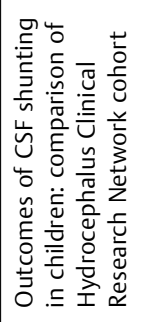 \\
\hline 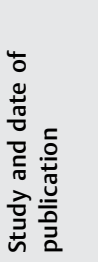 & & 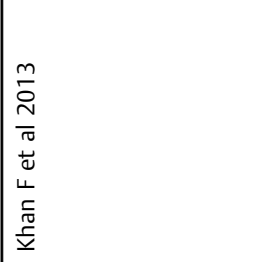 & 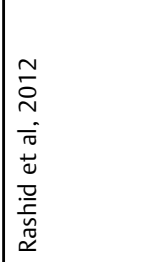 & 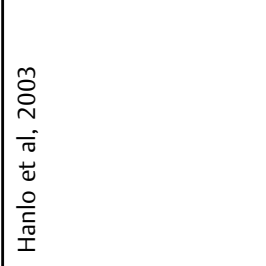 & 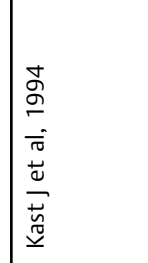 & 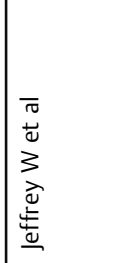 & 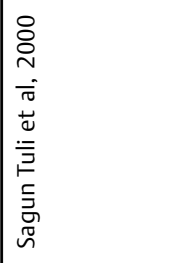 & 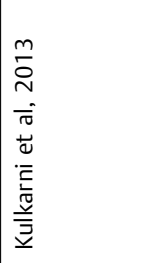 \\
\hline
\end{tabular}




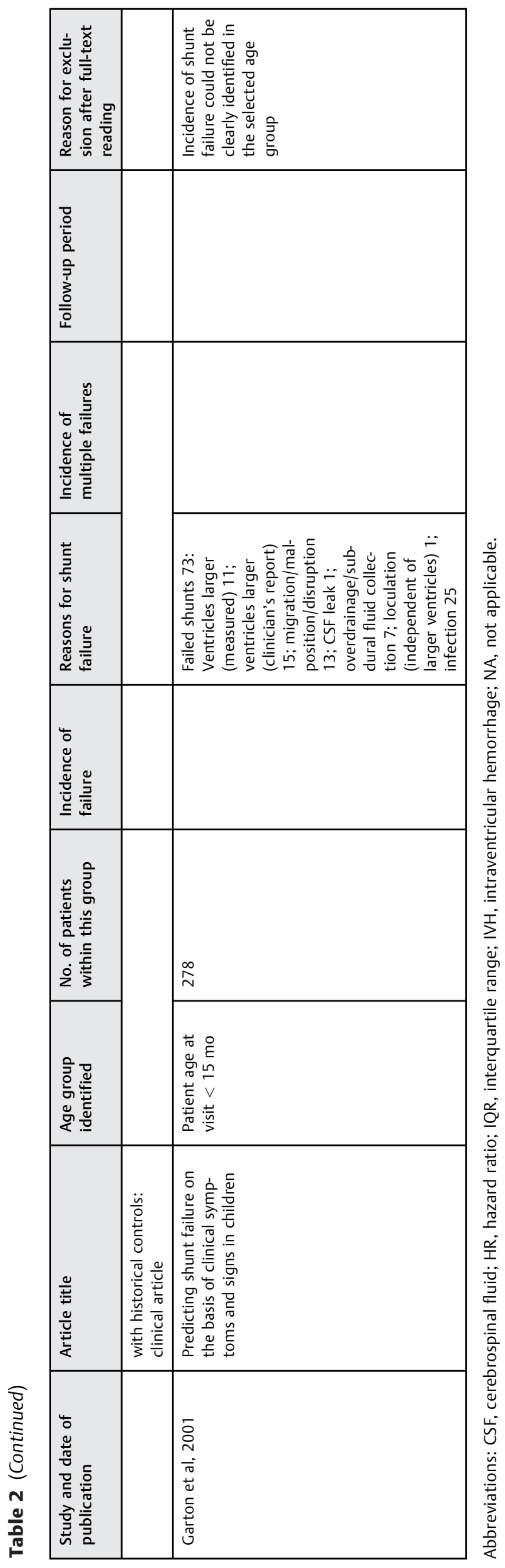

preterm-related post-hemorrhagic hydrocephalus was high but did not seem to be higher than in other groups with pediatric hydrocephalus. $^{2}$

The current study review confirms what has become common sense that most VP shunt failures are actually caused either by obstruction or infection, rather than by other causes of shunt failure such as valve problems, migration, or disconnection.

This study also approves what is well recognized by pediatric neurosurgeons that talking about shunt failure mostly involves the patients in the first year of life, at which the alternative management methods such as ETV also have a remarkable failure rate.

Further studies for the most common complications detected in this review are warranted. Shunt failure due to inadequate peritoneal absorption capacity in infants, as well as proximal obstruction, would be the most important issues to be covered in further clinical studies. ${ }^{16-22}$

\section{Conclusions}

The risk of shunt failure is highest during the first year after implanting a VP shunt, particularly in premature infants and infants during their first year of life. Many factors have a direct impact on shunt malfunction, among which mechanical obstruction and shunt infection were the most frequent.

All types of mechanical problems were reported including proximal obstructions, distal obstructions, disconnections, disruptions, and valve-related problems. Shunt failure was more frequent due to proximal or distal obstruction than valve dysfunction. Ongoing and future studies of shunt failure should focus on independently avoiding the two major causes of shunt failure that this review has identified.

\section{Funding Source}

The German Academic Exchange Service has funded a project to develop evidence-based guidelines for the prevention of VP shunt failure among infants. As part of this project, we performed this systematic review. 8

\section{Conflict of Interest}

None.

\section{References}

1 Bakhsh A. CSF shunt complications in infants-an experience from Pakistan. Pediatr Neurosurg 2011;47(02):93-98

2 Miranda P, Simal JA, Menor F, Plaza E, Conde R, Botella C. Initial proximal obstruction of ventriculoperitoneal shunt in patients with preterm-related posthaemorrhagic hydrocephalus. Pediatr Neurosurg 2011;47(02):88-92

3 Garber ST, Riva-Cambrin J, Bishop FS, Brockmeyer DL. Comparing fourth ventricle shunt survival after placement via stereotactic transtentorial and suboccipital approaches. J Neurosurg Pediatr 2013;11(06):623-629

4 Jernigan SC, Berry JG, Graham DA, Goumnerova L. The comparative effectiveness of ventricular shunt placement versus endoscopic third ventriculostomy for initial treatment of hydrocephalus in infants. J Neurosurg Pediatr 2014;13(03):295-300 
5 Di Rocco C, Massimi L, Tamburrini G. Shunts vs endoscopic third ventriculostomy in infants: are there different types and/or rates of complications? A review. Childs Nerv Syst 2006;22(12): 1573-1589

6 Guillaume D, Menezes A. Hydrocephalus in Chiari malformation and other craniovertebral junction abnormalities. In: Cerebrospinal Fluid Disorders. Boca Raton, FLCRC Press2009:300-317. Available at: http://www.crcnetbase.com/doi/abs/10.3109/9781420016284-18

7 Rabinstein AA, Jr MPK. Year Book of Neurology and Neurosurgery e-book. Elsevier Health Sciences; 2011

8 Programmlinie 4: Deutsch-Arabische Forschungspartnerschaft - Al Tawasul - DAAD - Deutscher Akademischer Austauschdienst. Available at: https://www.daad.de/hochschulen/programme-regional/ arabischer-raum/de/42005-programmlinie-deutsch-arabische-for schungspartnerschaft-al-tawasul/

9 Shannon CN, Acakpo-Satchivi L, Kirby RS, Franklin FA, Wellons JC. Ventriculoperitoneal shunt failure: an institutional review of 2-year survival rates. Childs Nerv Syst 2012;28(12):2093-2099

10 Beez T, Sarikaya-Seiwert S, Bellstädt L, Mühmer M, Steiger H-J. Role of ventriculoperitoneal shunt valve design in the treatment of pediatric hydrocephalus-a single center study of valve performance in the clinical setting. Childs Nerv Syst 2014;30(02): 293-297

11 Turhan T, Ersahin Y, Dinc M, Mutluer S. Cerebro-spinal fluid shunt revisions, importance of the symptoms and shunt structure. Turk Neurosurg 2011;21(01):66-73

12 Simon TD, Butler J, Whitlock KB, et al; Hydrocephalus Clinical Research Network. Risk factors for first cerebrospinal fluid shunt infection: findings from a multi-center prospective cohort study. J Pediatr 2014;164(06):1462-8.e2

13 Notarianni C, Vannemreddy P, Caldito G, et al. Congenital hydrocephalus and ventriculoperitoneal shunts: influence of etiology and programmable shunts on revisions. J Neurosurg Pediatr 2009; $4(06): 547-552$
14 Kulkarni AV, Riva-Cambrin J, Butler J, et al; Hydrocephalus Clinical Research Network. Outcomes of CSF shunting in children: comparison of Hydrocephalus Clinical Research Network cohort with historical controls: clinical article. J Neurosurg Pediatr 2013;12 (04):334-338

15 Riva-Cambrin J, Kestle JRW, Holubkov R, et al; Hydrocephalus Clinical Research Network. Risk factors for shunt malfunction in pediatric hydrocephalus: a multicenter prospective cohort study. J Neurosurg Pediatr 2016;17(04):382-390

16 Griffith HB, Jamjoom AB. The treatment of childhood hydrocephalus by choroid plexus coagulation and artificial cerebrospinal fluid perfusion. Br J Neurosurg 1990;4(02):95-100

17 Pople IK, Ettles D. The role of endoscopic choroid plexus coagulation in the management of hydrocephalus. Neurosurgery 1995;36 (04):698-701; discussion 701-702

18 Putnam TJ. Treatment of hydrocephalus by endoscopic coagulation of the choroid plexus-description of a new instrument and preliminary report of results. N Engl J Med 1934;210:1373-1376. Available at: http://www.nejm.org/doi/full/10.1056/NEJM1934062 82102602

19 Turner R, Chahlavi A, Rasmussen P, Brody F. Laparoscopic revision of a ventriculoperitoneal shunt. J Laparoendosc Adv Surg Tech A 2004;14(05):310-312

20 Warf BC. Comparison of endoscopic third ventriculostomy alone and combined with choroid plexus cauterization in infants younger than 1 year of age: a prospective study in 550 African children. J Neurosurg 2005;103(6, Suppl):475-481

21 Yavuz C, Demirtas S, Calıskan A, et al. Reasons, procedures, and outcomes in ventriculoatrial shunts: a single-center experience. Surg Neurol Int 2013. Ab; Available at: http://www.ncbi.nlm.nih. gov/pmc/articles/PMC3589837/

22 Yu S, Bensard DD, Partrick DA, Petty JK, Karrer FM, Hendrickson RJ. Laparoscopic guidance or revision of ventriculoperitoneal shunts in children. JSLS 2006;10(01):122-125 